\title{
BMJ Open Socioeconomic and lifestyle factors associated with hearing loss in older adults: a cross-sectional study of the English Longitudinal Study of Ageing (ELSA)
}

\author{
Dialechti Tsimpida, ${ }^{\circ}$ Evangelos Kontopantelis, ${ }^{\circ}{ }^{2}$ Darren Ashcroft, ${ }^{3}$ \\ Maria Panagioti ${ }^{4}$
}

To cite: Tsimpida D, Kontopantelis E, Ashcroft D, et al. Socioeconomic and lifestyle factors associated with hearing loss in older adults: a cross-sectional study of the English Longitudinal Study of Ageing (ELSA). BMJ Open 2019;9:e031030. doi:10.1136/ bmjopen-2019-031030

\section{- Prepublication history for} this paper is available online. To view these files, please visit the journal online (http://dx.doi. org/10.1136/bmjopen-2019031030).

Received 13 April 2019 Revised 15 August 2019 Accepted 21 August 2019

D) Check for updates

(c) Author(s) (or their employer(s)) 2019. Re-use permitted under CC BY. Published by BMJ.

For numbered affiliations see end of article.

\section{Correspondence to} Ms Dialechti Tsimpida; dialechti.tsimpida@manchester. ac.uk

\section{ABSTRACT}

Objectives Aims were (1) to examine whether socioeconomic position (SEP) is associated with hearing loss (HL) among older adults in England and (2) whether major modifiable lifestyle factors (high body mass index, physical inactivity, tobacco consumption and alcohol intake above the low-risk-level guidelines) are associated with HL after controlling for non-modifiable demographic factors and SEP.

Setting We used data from the wave 7 of the English Longitudinal Study of Ageing, which is a longitudinal household survey dataset of a representative sample of people aged 50 and older.

Participants The final analytical sample was 8529 participants aged 50-89 that gave consent to have their hearing acuity objectively measured by a screening audiometry device and did not have any ear infection. Primary and secondary outcome measures $\mathrm{HL}$ defined as $>35 \mathrm{dBHL}$ at $3.0 \mathrm{kHz}$ (better-hearing ear). Those with $\mathrm{HL}$ were further subdivided into two categories depending on the number of tones heard at $3.0 \mathrm{kHz}$.

Results HL was identified in $32.1 \%$ of men and $22.3 \%$ of women aged 50-89. Those in a lower SEP were up to two times more likely to have $\mathrm{HL}$; the adjusted odds of $\mathrm{HL}$ were higher for those with no qualifications versus those with a degree/higher education (men: OR $1.87,95 \% \mathrm{Cl}$ 1.47 to 2.38 , women: $\mathrm{OR} 1.53,95 \% \mathrm{Cl} 1.21$ to 1.95 ), those in routine/manual occupations versus those in managerial/ professional occupations (men: $\mathrm{OR} 1.92,95 \% \mathrm{Cl} 1.43$ to 2.63, women: $\mathrm{OR} 1.25,95 \% \mathrm{Cl} 1.03$ to 1.54 ), and those in the lowest versus the highest income and wealth quintiles (men: OR 1.62, 95\% Cl 1.08 to 2.44, women: OR 1.36 , $95 \% \mathrm{Cl} 0.85$ to 2.16 , and men: $0 \mathrm{R} 1.72,95 \% \mathrm{Cl} 1.26$ to 2.35, women: $\mathrm{OR} 1.88,95 \% \mathrm{Cl} 1.37$ to 2.58 , respectively). All regression models showed that socioeconomic and the modifiable lifestyle factors were strongly associated with $\mathrm{HL}$ after controlling for age and gender.

Conclusions Socioeconomic and lifestyle factors are associated with $\mathrm{HL}$ among older adults as strongly as core demographic risk factors, such as age and gender. Socioeconomic inequalities and modifiable lifestyle behaviours need to be targeted by the health policy strategies, as an important step in designing interventions for individuals that face hearing health inequalities.

\section{Strengths and limitations of this study}

- The first study that focuses on modifiable lifestyle factors (such as high body mass index, physical inactivity, tobacco consumption and alcohol intake above the low-risk-level guidelines) associated with hearing loss $(\mathrm{HL})$ among older adults in England.

- Examines four different socioeconomic position (SEP) indicators to HL (education, occupation, income and wealth), instead of a proxy measure to reflect one's total SEP, capturing, therefore, most of the variation in socioeconomic stratification, to the objectively measured $\mathrm{HL}$ in older adults.

- The analyses were based on a representative cohort of 8529 participants contained in English Longitudinal Study of Ageing (ELSA), which is a rich resource of information on the dynamics of health, social, well-being and economic circumstances of the English population aged 50 and over.

- The ELSA dataset did not contain information concerning the occupational and social noise exposure, but we examined the association of manual occupations with $\mathrm{HL}$ and its attenuation by modifiable determinants including smoking habit, which is of a higher prevalence among those that work in routine and manual occupations in England.

- All the analysed factors explained less than one-third of the variance for the prevalence of $H L$ suggesting that there are additional major factors associated with $\mathrm{HL}$ in older adults which have not been included in our analyses.

\section{INTRODUCTION}

Hearing loss (HL) is a major global health challenge and the most prevalent sensory disorder. Approximately 15\% of the global adult population has some degree of HL (of at least $\geq 25 \mathrm{~dB}$ HL in the better-hearing ear) ${ }^{1}$ and almost $7 \%$ has disabling HL (defined as a hearing threshold $\geq 40 \mathrm{~dB}$ HL in the better ear). ${ }^{2}$ HL has negative physical, social, 
cognitive, economic and emotional consequences and is the fourth leading contributor to years lived with disability worldwide. $^{2}$

Previous studies have reported that HL increases with age, ${ }^{3}$ exposure to high occupational and social noise ${ }^{4}$ and is more commonly in men. ${ }^{3}$ There is growing evidence that there are a number of modifiable risk factors for $\mathrm{HL},{ }^{56}$ and, if eliminated, half cases of HL could be prevented. ${ }^{2}$ Thus, there is a high potential for reducing the burden of HL, if we understand the modifiable factors and the mechanisms that lead to hearing health inequalities, which-following the glossary for health inequalities - could be defined as the avoidable differences in people's hearing health across different social and/or population groups.

Prior research has established health disparities in a wide range of health conditions according to socioeconomic position (SEP). ${ }^{8}$ Furthermore, there is an evidence that several modifiable lifestyle factors, such as smoking, ${ }^{9}$ alcohol consumption, ${ }^{10}$ high body mass index (BMI) and physical inactivity ${ }^{11}$ are associated with hearing health. Of course, causal paths have not been established, and these associations may be confounded by deprivation or aspects of deprivation (eg, type of occupation). Nevertheless, quantifying such associations is the first step in that direction; hearing health inequalities is an emerging research area and the existing evidence on the relationship of HL with SEP and modifiable lifestyle factors is scarce. There is a major public health need to assess whether $\mathrm{HL}$ is associated with SEP and lifestyle factors because this understanding could inform recommendations for HL preventative strategies. These could include wider implementation of interventions to promote 'healthier lifestyles', or governmental policies for socioeconomic equity among older people in the community.

The aims of this study were (1) to examine whether SEP is associated with HL among older adults in England and (2) whether major modifiable lifestyle factors are associated with HL after controlling for non-modifiable demographic factors and SEP in the analyses. This study is the first that examines four different SEP indicators (education, occupation, income and wealth) in HL, encompassing thus aspects of the life-course socioeconomic stratification, ${ }^{12}$ to the objectively measured HL in older adults. In addition, this is the first study that explores how major lifestyle factors for general health outcomes in the English population aged 50 years old and above (such as smoking, high BMI, insufficient physical activity, tobacco consumption and alcohol intake above the low-risk-level guidelines), ${ }^{1314}$ account for the variance in HL.

\section{METHODS}

\section{Study population}

The present study used data from the English Longitudinal Study of Ageing (ELSA). The ELSA is a longitudinal household survey dataset of a representative sample of people aged 50 and older in England. It is designed as a large-scale prospective cohort study, with repeat measures of core variables over numerous waves, in order to explore trajectories on the health, social, well-being and economic circumstances. ${ }^{15}$ The current sample contains data from up to eight waves of data collection covering a period of 15 years, with an ongoing 2-year follow-up longitudinal design. ${ }^{16}$

Objective hearing health data were available only in wave 7 , where information was collected from 9666 participants, between June 2014 and May 2015. For the purposes of this study, the final analytical sample was $\mathrm{n}=8529$ participants, aged $50-89$, that gave consent to have their hearing acuity measured by a screening audiometry device and did not have any ear infection or a cochlear implant.

\section{Patient and public involvement}

Patients were not involved in the conduct of the study.

\section{Hearing test}

A handheld audiometric screening device (HearCheck) ${ }^{17}$ was used for the objective measurement of hearing acuity. This is a portable and easy-to-use hearing screening test by Siemens that tests for audibility of pure tone beeps, according to the number of tones that the respondent can hear for each sequence (at $1.0 \mathrm{kHz}$ and $3.0 \mathrm{kHz}$ ), per each ear. The functional test sequence begins with a series of three sounds, which have decreasing volume at 1.0 $\mathrm{kHz}(55,34$ and $20 \mathrm{~dB}$ HL) and afterwards another three sounds with decreasing volume at $3.0 \mathrm{kHz}(75,55$ and 35 $\mathrm{dB} H L)$. Prerequisites for the test were the device to make proper contact with the ear that is tested, hearing $\operatorname{aid}(\mathrm{s})$, glasses, earrings and hair bands to be removed to prevent from getting in the way of the hearing device and the room to be as quiet as possible. Participants indicated when they hear the sound by raising their finger. The total number of tones that the participants indicated they could hear in the sequence of sounds at 1.0 and $3.0 \mathrm{kHz}$, per each ear, was recorded and the total tones heard in the better-hearing ear used for the categorisation of those with HL.

Previous studies have assessed the accuracy of the Siemens HearCheck in detecting HL and compared it with pure tone air conduction averages designated as gold-standard values. Fellizar-Lopez et al found that in cases of moderate or worse HL, the HearCheck test fulfils all criteria of high sensitivity rate, high specificity rate and high positive predictive values to be considered an accurate tool to screen for HL, without the need for soundproof audiometry booths. ${ }^{18}$

\section{Outcomes}

Hearing loss

HL was defined as $>35 \mathrm{~dB} \mathrm{HL}$ at $3.0 \mathrm{kHz}$, in the betterhearing ear. Those with HL were further subdivided into two categories depending on the number of tones heard at $3.0 \mathrm{kHz}$. This is the level where intervention for HL has shown to be definitely beneficial. ${ }^{19}$ For that reason, this categorisation has previously been used in the literature for the characterisation of those assessed by the same 
audiometric screening device (HearCheck). ${ }^{6}$ Thus, we further explored potential differences in the association between SEP indicators and HL, according to the severity of HL, as measured by HearCheck. The categorisation of those with HL was as following:

1. 'Moderate HL': tones heard at 75 and $55 \mathrm{~dB}$ HL but not at $35 \mathrm{~dB}$ HL (the first two of the three tones at 3.0 $\mathrm{kHz}$ heard),

2. 'Moderately severe or severe HL': tone heard or not at $75 \mathrm{~dB}$ HL and tones not heard at $55 \mathrm{~dB}$ HL and $35 \mathrm{~dB}$ HL ( 0 or 1 of the three tones at $3.0 \mathrm{kHz}$ heard).

The ordinal variable 'hearing acuity' (in the betterhearing ear) was consisted of the above two categories of HL and the category of 'normal hearing', which was defined as having heard all the three tones of the hearing screening test at $3.0 \mathrm{kHz}$.

\section{Indicators of SEP}

Education, occupation, income and wealth were the four selected indicators of SEP and information was collected in the seventh wave of ELSA, between June 2014 and May 2015. We considered five categories of the highest educational attainment: degree/higher education; A level (Level 3 of the National Qualifications Framework); O levels Certificate of Secondary Education; foreign/other; no qualifications. Tertiles of self-reported occupation were based on the National Statistics Socio-economic Classification: managerial and professional, intermediate, routine and manual occupations). The relative financial position of the participants was captured by quintiles of the net household income (first quintile lowest; fifth quintile highest) that is summed across household members. In order to avoid the information bias that is related to the retirement status, we used quintiles of the total non-pension wealth that is reported at the household level (first quintile lowest; fifth quintile highest), which represents the sum of net financial wealth, net physical wealth and net housing wealth.

\section{Covariates}

Age, marital status, retirement status and non-medical determinants of health (BMI, physical activity, tobacco and alcohol consumption) were assessed as covariates in the association between SEP indicators and HL. ${ }^{5}$

Age was categorised into three groups (50-64, 65-74 and 75-89), to allow for a comparison with Benova et $a l^{20}$ who examined the association of SEP with self-reported hearing difficulty in ELSA wave 2.

Marital status was dichotomised into those that are currently married or not. Those who are currently married included the categories (1) married, first and only marriage, (2) in a registered civil partnership and (3) remarried, in a second or later marriage. Those that categorised as not currently married included the categories (1) single, that is never married and never registered in a marriage, (2) separated, but still legally married, (3) divorced and (4) widowed.
Retirement status was dichotomised into those who were retired or not, according to the self-reported employment status.

BMI measurements were grouped in four categories, according to WHO definitions ${ }^{21}$ : (1) underweight: BMI under $18.5 \mathrm{~kg} / \mathrm{m}^{2}$, (2) normal: BMI $18.5 \mathrm{~kg} / \mathrm{m}^{2}$ or over but less than $25 \mathrm{~kg} / \mathrm{m}^{2}$, (3) overweight: BMI $25 \mathrm{~kg} / \mathrm{m}^{2}$ or over but less than 30 and (4) obese: BMI $30 \mathrm{~kg} / \mathrm{m}^{2}$ or over.

Tobacco consumption of any type of nicotine products was recoded into three categories: those that were current smokers, those that were former smokers and those that never smoked. Both current and former smokers answered the question of 'number of cigarettes smoked per day', to explore whether they were occasional or regular smokers.

Alcohol consumption was recorded using several continuous variables such as the number of days of alcohol consumption in the last 7 days and the number of (1) measures of spirit, (2) glasses of wine and (3) pints of beer that the respondents had consumed during this period. We constructed a continuous variable to represent the sum of units of alcohol that the participants consumed in the last 7 days, according to the Chief Medical Officer's Drinking Guidelines ${ }^{22}$ that counts as 1 unit each measure of spirit and as 2 units each glass of wine of pint of beer. The constructed variable of units of alcohol during the last 7 days was further dichotomised into those that consumed more than 14 units of alcohol the last 7 days or not, in a separate variable.

Levels of physical activity were described by three ordinal variables that examined the frequency that the respondents do rigorous, moderate or mild sports or activities, with possible answers (1) more than once a week, (2) once a week, (3) one to three times a month and (4) hardly ever or never.

\section{Statistical analysis}

Categorical variables are presented as absolute (n) and relative (\%) frequencies, while continuous variables are presented using their mean and SD. The Kolmogorov-Smirnov test and normal plots were used to test the normality of the quantitative variable distributions. All the 8529 individuals (of the 9666 initial sample in ELSA wave 7 ), had usable objective hearing data, measured by a qualified nurse. In total, 257 participants refused to have the assessment (the $2.6 \%$ of the full cohort of 9666 participants). As there was no pattern in the missing data regarding age, sex, education, occupation, income and wealth and due to low proportion of missingness $(<5 \%)$, records with missing data were dropped from the analyses.

We fitted multiple logistic regression models to evaluate the odds of HL at various socioeconomic strata, controlling for gender, age and non-medical determinants of health (BMI, physical activity, tobacco and alcohol consumption). Additionally, we fitted four separate stepwise logistic regression models, to examine the association of HL with non-modifiable (age, gender: step 
1), partly modifiable (education, occupation, income, wealth: step 2, respectively) and fully modifiable lifestyle risk factors (BMI, physical activity, tobacco and alcohol consumption: step 3). Age was entered into the multivariable logistic regression models as a continuous variable, to maximise power.

The variants of pseudo R-squared statistics were based on the deviance of the models and used to express how much variance in the outcome is explained by the variables in each stepwise multiple logistic regression model. The variance inflation factor (VIF) was used as an indicator of multicollinearity and the Hosmer-Lemeshow test was used as a post estimation tool, which quantified the goodness-of-fit of the models. For all models, ORs, 95\% CIs, unadjusted and adjusted coefficients' beta values, pseudo $\mathrm{R}^{2}$ and mean VIFs are presented. The two-tailed significance level was set $\leq 0.05$. All data were analysed using Stata V.14 (StataCorp, 2015) ${ }^{23}$

\section{RESULTS}

\section{Sociodemographic characteristics}

Overall, 26.6\% (2266/8529) of adults aged 50-89 had $\mathrm{HL}>35 \mathrm{~dB}$ HL at $3.0 \mathrm{kHz}$. The percentages were $32.1 \%$ $(1198 / 3728,95 \%$ CI $0.31 \%$ to $0.34 \%)$ for men and $22.3 \%$ (1068/4801, $95 \%$ CI $0.21 \%$ to $0.23 \%)$ for women, respectively. Table 1 shows the distribution of sociodemographic characteristics of the sample $(n=8529$, aged 50-89) according to hearing acuity. The proportion of men and women with $\mathrm{HL}>35 \mathrm{~dB} \mathrm{HL}$ at $3.0 \mathrm{kHz}$ was 52.8 (1198) and 47.2 (1068), respectively. However, men were 1.5 times more likely to have moderately severe or severe HL compared with women. One in three adults aged 65-75 had HL and the percentage of HL in age band 75-89 was threefold larger than in age band 50-64, as one out of every two adults aged 75-89 had HL $>35 \mathrm{~dB}$ HL at 3.0 $\mathrm{kHz}$.

\section{Lifestyle factors}

Lifestyle factors of the participants are presented in table 2. Over half of the participants were current or former smokers. In addition, patterns of high levels of alcohol consumption among all participants were revealed, with average consumption of more than 14 units of alcohol in the last 7 days for two out of three participants (5223/8528, 95\% CI 0.60 to 0.61$)$. Nearly one out of every three of those drinking above the low-risk-level guidelines $^{22}(1457 / 5.223,95 \%$ CI 0.27 to 0.29$)$ had HL $>35 \mathrm{~dB}$ HL at $3.0 \mathrm{kHz}$.

Three out of four of those with HL $>35 \mathrm{~dB}$ HL at 3.0 $\mathrm{kHz}$ were overweight or obese. Furthermore, those with $\mathrm{HL}>35 \mathrm{~dB}$ HL at $3.0 \mathrm{kHz}$ were twice as likely to hardly ever or never engage in moderate or mild sports activities compared with hearing participants.

\section{Hearing loss}

Table 3 and figure 1 show the results of multiple logistic regression analysis with $\mathrm{HL}>35 \mathrm{~dB} \mathrm{HL}$ at $3.0 \mathrm{kHz}$ as the dependent variable and SEP indicators as the independent variables, per each gender. The adjusted odds of HL were higher for those with no qualifications versus those with a degree/higher education (men: OR 1.87, 95\% CI 1.47 to 2.38 , women: OR $1.53,95 \%$ CI 1.21 to 1.95 ), those in routine/manual occupations versus those in manage$\mathrm{rial} /$ professional occupations (men: OR 1.92, 95\% CI 1.43 to 2.63 , women: OR $1.25,95 \%$ CI 1.03 to 1.54 ) and those in the lowest versus the highest income and wealth quintiles (men: OR 1.62, 95\% CI 1.08 to 2.44, women: OR $1.36,95 \%$ CI 0.85 to 2.16 and men: OR $1.72,95 \%$ CI 1.26 to 2.35, women: OR $1.88,95 \%$ CI 1.37 to 2.58 , respectively).

Table 4 shows the summary of stepwise logistic regression analysis for variables predicting $\mathrm{HL}>35 \mathrm{~dB}$ HL at 3.0 $\mathrm{kHz}$. All regression models were statistically significant. Age and gender only explained about $15 \%$ of the variance in the likelihood of HL. The addition of lifestyle factors attenuated significantly the association between the HL and SEP indicators and in total the addition of SEP and lifestyle factors in the regression models explained another $10 \%-15 \%$ of the variance in the likelihood of HL. The total variance explained in the overall models containing demographic factors, SEP and lifestyle factors ranged between $25 \%$ and $27 \%$. This finding suggests that SEP and lifestyle factors have an equal contribution to HL as age and gender.

The differences in HL prevalence between males and females were observed across all age bands investigated. However, we noticed that the rate of deterioration of hearing acuity as age increases was similar between each age band and nearly to $60 \%$ in both genders (figure 2). The difference in prevalence begins at the age band '50-64', where men were twice as likely to have HL.

\section{DISCUSSION}

\section{Summary of main findings}

In this study, we examined whether SEP and modifiable lifestyle factors are associated with HL among older adults in England. We found that variation in education, occupation, income and wealth, which are important determinants of health inequality, are associated with HL. SEP was strongly associated with the likelihood of HL in older adults, with the higher levels of education, income and wealth being less likely to be associated with HL, and the manual occupations increased the likelihood of HL. We also found that socioeconomic and several modifiable lifestyle factors (such as high BMI, physical inactivity, tobacco consumption and alcohol intake above the low-risk-level guidelines ${ }^{22}$ are associated with the likelihood of HL as strongly as well-established demographic factors such as age and gender HL. These findings suggest that a large proportion of HL burden is potentially preventable and support the proposition of Scholes $e t$ a $t^{6}$ that there is serious potential to reduce the prevalence and impacts of HL by understanding the impact of socioeconomic inequality in hearing health. Thus, the incidence 
Table 1 Participants sociodemographic characteristics ( $N=8529$, aged 50-89)

\begin{tabular}{|c|c|c|c|c|}
\hline \multirow[b]{2}{*}{ Variable } & \multicolumn{4}{|c|}{ Hearing acuity $\%(\mathrm{~N})$ in the better-hearing ear } \\
\hline & Normal hearing & $\begin{array}{l}\mathrm{HL}>35 \mathrm{~dB} \text { HL at } 3.0 \\
\mathrm{kHz}\end{array}$ & Moderate $\mathrm{HL}^{*}$ & $\begin{array}{l}\text { Moderately severe } \\
\text { or severe HL† }\end{array}$ \\
\hline Male & $40.4(2530)$ & $52.8(1198)$ & $49.5(741)$ & $59.5(457)$ \\
\hline Female & $59.6(3733)$ & $47.2(1068)$ & $50.5(757)$ & $40.5(311)$ \\
\hline $50-64$ & $51.3(3135)$ & $16.2(349)$ & $19.3(280)$ & $9.8(69)$ \\
\hline $65-74$ & $34.55(2108)$ & $33.6(722)$ & $36.9(535)$ & $26.7(187)$ \\
\hline $75-89$ & $14.2(868)$ & $50.2(1081)$ & $43.8(636)$ & $63.5(445)$ \\
\hline \multicolumn{5}{|l|}{ Currently married } \\
\hline Retired & $52.4(3205)$ & $78.3(1685)$ & $76.6(1112)$ & $81.3(573)$ \\
\hline Not retired & $47.6(2905)$ & $21.7(467)$ & 23.4 (339) & $18.3(128)$ \\
\hline \multicolumn{5}{|l|}{ Education } \\
\hline Degree/higher education & 33.7 (1996) & $26.4(562)$ & $28.1(404)$ & $22.9(158)$ \\
\hline A level & $10.0(596)$ & $6.4(137)$ & $7.0(100)$ & $5.4(37)$ \\
\hline O level/CSE grade & $24.4(1448)$ & $22.3(473)$ & $22.4(321)$ & $22.0(152)$ \\
\hline Foreign/other & $13.5(798)$ & $11.9(252)$ & $11.9(171)$ & $11.7(81)$ \\
\hline No qualifications & $18.4(1090)$ & $33.0(701)$ & $30.6(439)$ & $38.0(262)$ \\
\hline \multicolumn{5}{|l|}{ Net household income } \\
\hline First quintile (lowest) & $17.0(872)$ & $21.3(421)$ & $19.7(262)$ & $24.8(159)$ \\
\hline Second quintile & 18.7 (959) & $24.8(489)$ & 24.7 (329) & $24.9(160)$ \\
\hline Third quintile & $20.1(1034)$ & $23.0(453)$ & $22.3(297)$ & $24.3(156)$ \\
\hline Fourth quintile & $22.5(1154)$ & $18.6(367)$ & $19.9(265)$ & $15.9(102)$ \\
\hline Fifth quintile (highest) & $21.7(1112)$ & $12.3(243)$ & $13.4(178)$ & $10.1(65)$ \\
\hline \multicolumn{5}{|l|}{ Net financial wealth } \\
\hline First quintile (lowest) & $15.5(794)$ & $14.7(290)$ & 14.9 (199) & $14.2(91)$ \\
\hline Second quintile & $17.1(879)$ & $24.1(475)$ & $22.1(294)$ & $28.2(181)$ \\
\hline Third quintile & $19.6(1006)$ & $23.6(466)$ & $23.4(311)$ & $24.1(155)$ \\
\hline Fourth quintile & $23.5(1204)$ & $20.3(400)$ & $21.3(284)$ & $18.1(116)$ \\
\hline Fifth quintile (highest) & 24.3 (1248) & $17.3(342)$ & $18.3(243)$ & $15.4(99)$ \\
\hline
\end{tabular}

Values are expressed as column \% (N) unless otherwise is indicated.

*Moderate HL: tones heard at $75 \mathrm{~dB} \mathrm{HL}$ and $55 \mathrm{~dB} \mathrm{HL}$ but not at $35 \mathrm{~dB} \mathrm{HL}$ (the first two of the three tones at $3.0 \mathrm{kHz}$ heard).

†Moderately severe or severe $\mathrm{HL}$ : tone heard or not at $75 \mathrm{~dB} \mathrm{HL}$ and tones not heard at $55 \mathrm{~dB} \mathrm{HL}$ and $35 \mathrm{~dB} \mathrm{HL}(0$ or 1 of the three tones at $3.0 \mathrm{kHz}$ heard).

$\ddagger$ Mean (SD).

CSE, Certificate of Secondary Education; HL, hearing loss. 
Table 2 Participants' lifestyle factors ( $N=8529$, aged $50-89$ )

\begin{tabular}{|c|c|c|c|c|}
\hline \multirow[b]{2}{*}{ Variable } & \multicolumn{4}{|c|}{ Hearing acuity \% $(\mathrm{N})$ in the better-hearing ear } \\
\hline & Normal hearing & $\begin{array}{l}\mathrm{HL}>35 \mathrm{~dB} \mathrm{HL} \text { at } \\
3.0 \mathrm{kHz}\end{array}$ & $\begin{array}{l}\text { Moderate } \\
\text { HL* }^{*}\end{array}$ & $\begin{array}{l}\text { Moderately severe } \\
\text { or severe HL† }\end{array}$ \\
\hline \multicolumn{5}{|c|}{ Tobacco consumption (any type of nicotine products) } \\
\hline Current & $11.7(712)$ & $10.0(215)$ & $9.6(139)$ & $10.8(76)$ \\
\hline Former & $49.0(2996)$ & $56.7(1219)$ & $55.8(810)$ & $58.4(409)$ \\
\hline No of cigarettes smoked per day $\ddagger$ & $12.79(14)$ & $12.79(13)$ & $12.69(13)$ & $11.90(12)$ \\
\hline Never & $39.3(2403)$ & $33.3(718)$ & $34.6(502)$ & $30.8(216)$ \\
\hline \multicolumn{5}{|l|}{ Alcohol consumption (in the last 7 days) } \\
\hline No of days of alcohol consumption§ & $3(3)$ & $3(4)$ & $3(4)$ & $3(4)$ \\
\hline No of measures of spiritł & $2.1(2)$ & $2.3(3)$ & $2.2(3)$ & $2.6(3)$ \\
\hline No of glasses of wineł & $4.3(6)$ & $3.6(5)$ & $3.9(6)$ & $3.1(4)$ \\
\hline No of pints of beer $\ddagger$ & $2.1(2)$ & $2.3(3)$ & $2.3(3)$ & $2.4(3)$ \\
\hline Total units of alcohol in the last 7 days $\neq$ & $15.0(18)$ & $14.2(19)$ & $14.5(21)$ & $13.5(17)$ \\
\hline Consumption of more than 14 units & $61.6(3766)$ & $67.7(1457)$ & $67.3(977)$ & $68.5(480)$ \\
\hline \multicolumn{5}{|l|}{ BMI Classification } \\
\hline Underweight & $3.4(160)$ & $5.0(92)$ & $4.9(60)$ & $5.3(32)$ \\
\hline Normal & $26.9(1255)$ & $20.6(376)$ & $19.6(239)$ & $22.7(137)$ \\
\hline Overweight & 40.0 (1869) & $42.8(780)$ & $41.4(506)$ & $45.4(274)$ \\
\hline Obese & $29.7(1390)$ & $31.6(576)$ & $34.1(416)$ & $26.6(160)$ \\
\hline \multicolumn{5}{|l|}{ Physical activity } \\
\hline \multicolumn{5}{|c|}{ Frequency does rigorous sports or activities } \\
\hline More than once a week & $23.0(1407)$ & $14.3(307)$ & $16.1(233)$ & $10.6(74)$ \\
\hline Once a week & $10.3(626)$ & $7.0(151)$ & $7.9(115)$ & $5.1(36)$ \\
\hline One to three times a month & $10.1(617)$ & $7.1(153)$ & $7.6(111)$ & $6.0(42)$ \\
\hline Hardly ever or never & $56.6(3459)$ & $71.6(1541)$ & $68.4(992)$ & $78.3(549)$ \\
\hline More than once a week & $68.4(4180)$ & $51.3(1104)$ & $53.7(780)$ & $46.2(324)$ \\
\hline Once a week & $12.6(771)$ & $13.6(292)$ & $14.1(204)$ & $12.6(88)$ \\
\hline One to three times a month & $5.9(360)$ & $7.8(169)$ & $7.6(110)$ & $8.4(59)$ \\
\hline Hardly ever or never & $13.1(799)$ & $27.3(587)$ & $24.6(357)$ & $32.8(230)$ \\
\hline \multicolumn{5}{|l|}{ Frequency does mild sports or activities } \\
\hline More than once a week & 83.9 & 73.7 & $76.0(1103)$ & $68.9(483)$ \\
\hline Once a week & 8.2 & 10.1 & $9.8(142)$ & $10.5(74)$ \\
\hline One to three times a month & 2.3 & 3.5 & $3.3(48)$ & $4.0(28)$ \\
\hline Hardly ever, or never & 5.6 & 12.7 & $10.9(158)$ & $16.6(116)$ \\
\hline
\end{tabular}

Values are expressed as column \% (N) unless otherwise is indicated.

*Moderate $\mathrm{HL}$ : tones heard at $75 \mathrm{~dB} \mathrm{HL}$ and $55 \mathrm{~dB} \mathrm{HL}$ but not at $35 \mathrm{~dB} \mathrm{HL}$ (the first two of the three tones at $3.0 \mathrm{kHz}$ heard).

†Moderately severe or severe $\mathrm{HL}$ : tone heard or not at $75 \mathrm{~dB} \mathrm{HL}$ and tones not heard at $55 \mathrm{~dB} \mathrm{HL}$ and $35 \mathrm{~dB} \mathrm{HL}(0$ or 1 of the three tones at $3.0 \mathrm{kHz}$ heard).

‡Mean (SD).

$\S$ Median (Range).

BMI, body mass index; HL, hearing loss.

and severity of HL in England could be significantly reduced by the governmental policies to mitigate socioeconomic disparities and public health interventions to promote healthier lifestyles in middle-aged and older adults in England. The occurrence of objective hearing data eliminated the different types of bias that occur in self-reporting hearing difficulties, ${ }^{24}$ strengthening the accuracy of findings.

\section{Strengths and limitations}

The main strength of our study was that is the first to examine the association of four separate SEP indicators 
Table 3 Multiple logistic regression analysis of $n=8529$, aged 50-89 with $\mathrm{HL}>35 \mathrm{~dB} \mathrm{HL}$ at $3.0 \mathrm{kHz}$ in better-hearing ear as dependent variable and SEP indicators as independent variables

\begin{tabular}{|c|c|c|c|c|}
\hline & \multicolumn{2}{|c|}{ Unadjusted OR $(95 \% \mathrm{Cl})^{*}$} & \multicolumn{2}{|c|}{ Adjusted OR (95\% Cl)† } \\
\hline & Men & Women & Men & Women \\
\hline \multicolumn{5}{|l|}{ Education } \\
\hline Foreign/other & 1.06 (0.83 to 1.36$)$ & 1.37 (1.07 to 1.74$)$ & 1.46 (1.09 to 1.94$)$ & 0.99 (0.74 to 1.32$)$ \\
\hline O level/CSE grade & $1.56(1.29$ to 1.89$)$ & 1.00 (0.80 to 1.25$)$ & $1.42(1.13$ to 1.79$)$ & 0.94 (0.73 to 1.22$)$ \\
\hline \multicolumn{5}{|l|}{ Degree/higher education (reference) } \\
\hline \multicolumn{5}{|c|}{ Occupation based National Statistics Socioeconomic Classification } \\
\hline Routine and manual occupations & 1.69 (1.39 to 2.08$)$ & 1.35 (1.15 to 1.59$)$ & 1.92 (1.43 to 2.63$)$ & 1.25 (1.03 to 1.54$)$ \\
\hline $\begin{array}{l}\text { Intermediate occupations (non- } \\
\text { manual) }\end{array}$ & $1.47(1.23$ to 1.75$)$ & 1.54 (1.19 to 1.96$)$ & 1.61 (1.25 to 2.08$)$ & 1.35 (1.01 to1.85) \\
\hline Second quintile & 2.12 (1.67 to 2.70$)$ & 3.00 (2.28 to 3.93$)$ & $1.31(0.93$ to 1.85$)$ & 1.40 (0.89 to 2.18$)$ \\
\hline Third quintile & 1.98 (1.56 to 2.51$)$ & 2.31 (1.75 to 3.05$)$ & $1.40(1.01$ to 1.94$)$ & 1.08 (0.69 to 1.67$)$ \\
\hline Fourth quintile & 1.38 (1.08 to 1.74$)$ & 1.65 (1.23 to 2.20$)$ & 1.09 (0.80 to 1.49$)$ & $1.08(0.70$ to 1.66$)$ \\
\hline \multicolumn{5}{|l|}{ Fifth quintile (highest) (reference) } \\
\hline \multicolumn{5}{|l|}{ Net financial wealth } \\
\hline First quintile (lowest) & $1.11(0.86$ to 1.45$)$ & 1.79 (1.38 to 2.33$)$ & 1.72 (1.26 to 2.35$)$ & 1.88 (1.37 tro 2.58) \\
\hline Second quintile & 1.92 (1.52 to 2.42$)$ & 2.39 (1.88 to 3.04$)$ & 1.66 (1.26 to 2.18$)$ & $1.33(1.00$ to 1.77$)$ \\
\hline Third quintile & 1.63 (1.30 to 2.04$)$ & 1.95 (1.53 to 2.50$)$ & 1.45 (1.12 to 1.88$)$ & 1.41 (1.06 to 1.88$)$ \\
\hline
\end{tabular}

*Unadjusted OR

†OR adjusted for age, marital status, retirement status, body mass index, tobacco consumption, alcohol consumption and physical activity. CSE, Certificate of Secondary Education; HL, hearing loss; SEP, socioeconomic position.

with HL among older adults in England, instead of a proxy measure to reflect one's total SEP, capturing, therefore, most of the variation in socioeconomic stratification $^{12}$ and also the role of modifiable lifestyle risk factors in these associations. Another strength is that the analyses were based on a representative cohort of 8529 participants contained in ELSA, which is a rich resource of information on the dynamics of health, social, well-being and economic circumstances in the English population aged 50 and older. ${ }^{16}$

However, there are also important limitations. First, no causal or temporal relationships can be established between lifestyle factors and HL in this cross-sectional study. Unhealthy lifestyle behaviours could lead to HL in older people but is also possible that older people adopt less healthy lifestyles after HL. Second, all the analysed factors explained less than one-third of the variance for the prevalence of HL suggesting that there are additional major factors associated with HL in older adults which have not been included in our analyses. Longitudinal analyses using a broader range of physical health, mental health and social care variables are highly recommended to obtain a comprehensive understanding of modifiable factors which contribute to HL among older adults in England. Third, the ELSA dataset did not include information concerning the occupational and social noise exposure, which has a damaging effect in hearing. ${ }^{4}$ We, therefore, were not able to examine the association of noise exposure with smoking in the relationship of SEP with $\mathrm{HL}$, as in a previous study which found that the smoking habit in workers exposed to occupational noise greatly influenced HL. ${ }^{25}$ However, we examined the association of manual occupations with $\mathrm{HL}$ and its attenuation by modifiable determinants including smoking habit, which is of a higher prevalence among those that work in routine and manual occupations in England. ${ }^{13}$ Finally, we did not run weighted analyses which may have reduced the generalisability of our findings, as the ELSA sample members at wave 7 could be healthier on average than the population, potentially resulting in an underestimation of relationships. 


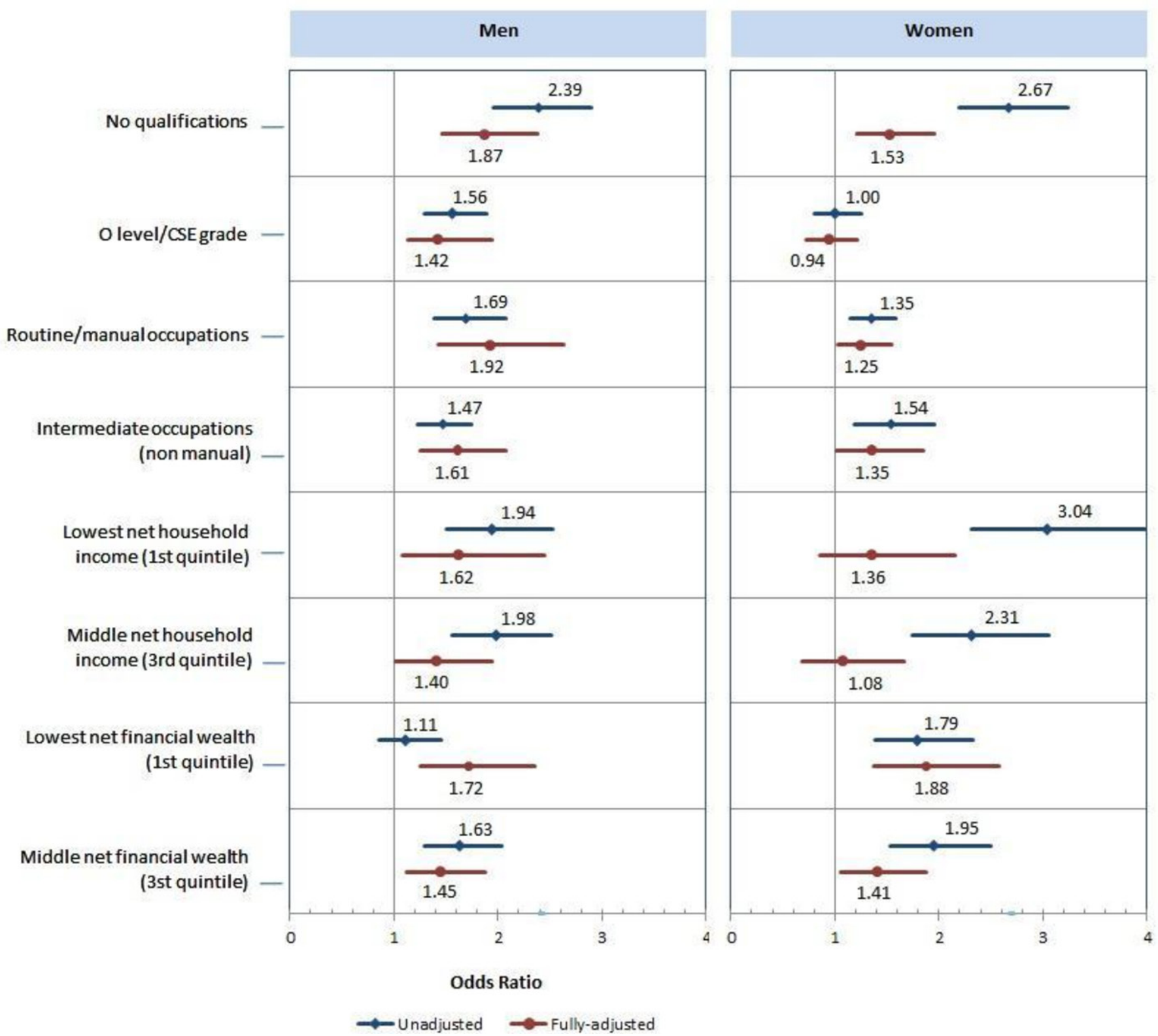

Figure 1 Associations between socioeconomic position and hearing loss in middle-aged and older adults ( $\mathrm{n}=8529$, aged $50-$ 89). Indicators of SEP were categories of the highest educational attainment (degree/higher education as a reference), tertiles of self-reported occupation based on the National Statistics Socio-economic Classification (managerial and professional as reference), quintiles of the net household income (first quintile lowest; fifth quintile highest) and quintiles of the total non-pension wealth that is reported at the household level (first quintile lowest; fifth quintile highest). lines represent or (outcome=hearing loss) and its $95 \% \mathrm{Cl}$. Model A (rhombus): unadjusted. model B (circles): adjusted for age, marital status, retirement status, body mass index, tobacco consumption, alcohol consumption and physical activity. CSE, Certificate of Secondary Education; SEP, socioeconomic position.

\section{Research and policy implications}

A number of previous studies have reported that the odds of HL in older adults were significantly increased for those with lower educational attainment. ${ }^{6} 102627$ VS and those in manual versus non-manual occupations, ${ }^{28-31}$ Besides, income is a correlate of HL, with the prevalence of untreated HL being higher among low-income older adults in the USA. ${ }^{31}$ In our study, those in the lowest quintile of net household income had disproportionally higher percentages of moderate HL compared with moderately severe or severe HL, but this pattern was not found in the quintiles of wealth, as expected. This may indicate a possible delay in diagnosis of hearing problems among those in lower SEP due to financial barriers in access to health services, ${ }^{32}$ which needs further exploration, as HL is highly undiagnosed and untreated among older adults in England. ${ }^{20}$

International studies have also shown that tobacco consumption, high body mass and high fat and high calorie food consumption can have an adverse impact on hearing, ${ }^{11}{ }^{33-35}$ On the other hand, a higher level of physical activity is related with a lower risk of HL. ${ }^{34} \mathrm{In}$ our 


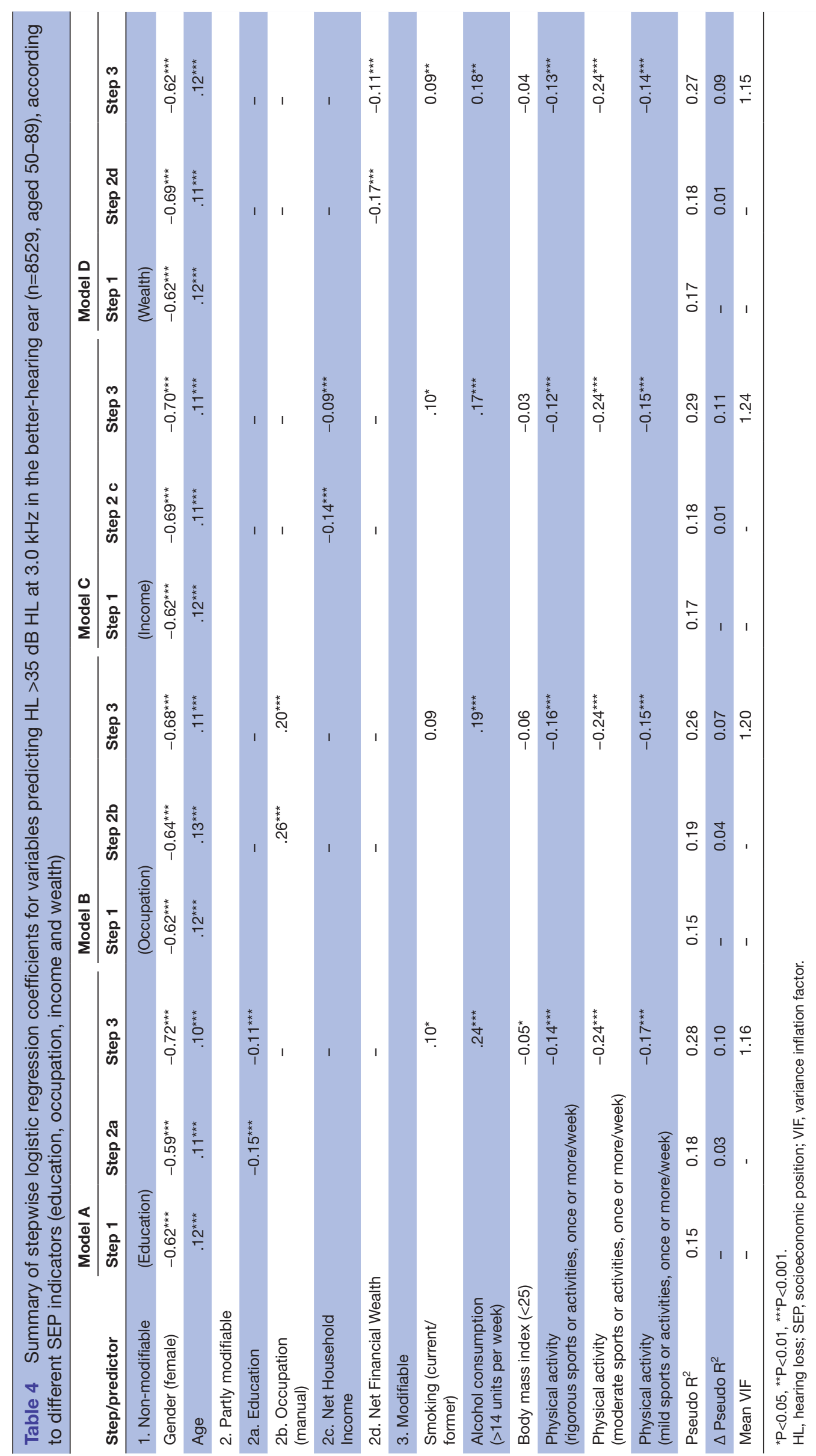

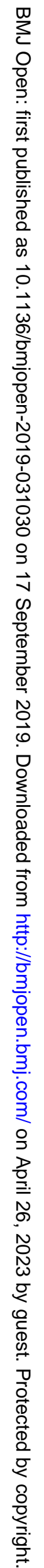




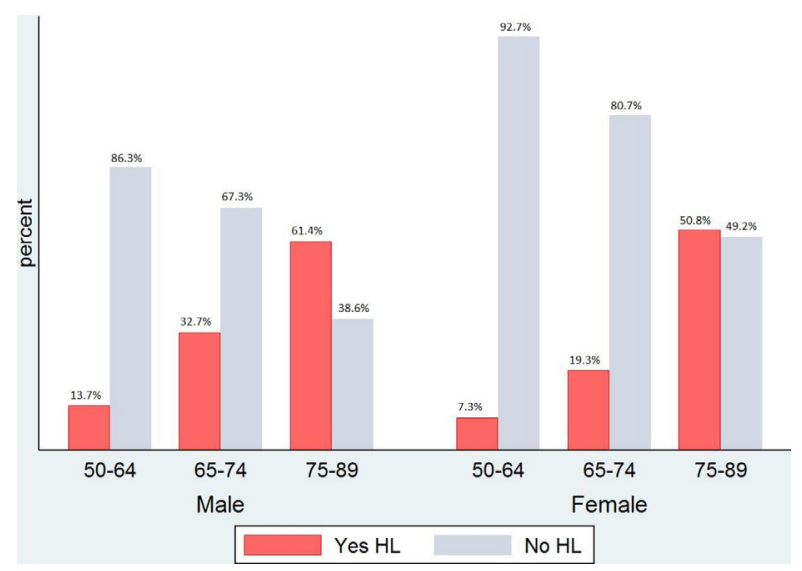

Figure 2 Hearing loss (HL) by age group and gender* $(n=8529$ participants, aged 50-89, from the seventh wave of the English Longitudinal Study of Ageing. $\mathrm{HL}$ was defined as $>35 \mathrm{~dB} \mathrm{HL}$ at $3.0 \mathrm{kHz}$, in the better-hearing ear. ${ }^{*}$ Prevalence estimates for males $(\mathrm{N}=3728)$ and females $(\mathrm{N}=4801)$.

study, two out of three participants were drinking more than the low-risk level of the 14 units of alcohol a week. ${ }^{22}$ We considered, therefore, that alcohol consumption above the low-risk-level guidelines may play an important role in the association between SEP and HL among the English population and thus we included this variable in the regression models, which has not been previously examined in the literature for the English population. Our findings showed that drinking above the low-risk-level guidelines increased the likelihood of HL. This finding is in line with Chief Medical Officer's Drinking guidelines, ${ }^{22}$ which suggest that it is safest not to drink regularly more than 14 units per week, to keep health risks from drinking alcohol to a low level.

The associations between indicators of lower SEP and HL may be markers of less healthy lifestyle, ${ }^{5}$ which may explain the link between HL and socioeconomic and lifestyle factors investigated. Cruickshanks $e t a p^{36} \mathrm{did}$ not find significant associations between hearing impairment and BMI, smoking and alcohol in the multivariable analyses using a younger population-based sample (aged 18-74 years) of Hispanics/Latinos. Hence, it is likely that HL in older population (eg, 50 years and above) is associated with different risk factors or combinations of socioeconomic and lifestyle risk factors across the life course.

The higher prevalence of HL among men aged 50 and above compared with women has also been reported in other studies. ${ }^{36}$ However, we observed that the rate of deterioration of hearing acuity as age increases was similar between each age band and nearly to $60 \%$ in both genders. The difference in prevalence begins at the age band ' $50-64$ ', where men were twice as likely to have HL. Thus, the differences in modifiable lifestyle factors that were revealed in the stepwise regression models may finally explain why the male sex is often cited as consistent risk factor for $\mathrm{HL},{ }^{35-37}$ leading to the exploration of modifiable determinants that are common in both genders $^{5}$ and paving the way for interventions to improve the population's hearing health.

In terms of policy, generating evidence concerning the critical variables associated with HL is an important step in designing targeted services and interventions for individuals that face hearing health inequalities, and especially, for those in the lowest SEP groups, where the burden of HL falls highest. This is of major importance for the population in England, as sensor diseases are the first leading cause of morbidity among adults 70 years and older and the second leading cause among adults $50-69$ years. ${ }^{13}$ Our findings support the view that HL is a non-communicable disease, ${ }^{38}$ which can be prevented or ameliorated by the governmental policies to mitigate socioeconomic disparities and public health interventions to promote healthier lifestyles in middle-aged and older adults in England.

\section{CONCLUSION}

The main finding of our study is that HL is strongly associated with socioeconomic factors and modifiable lifestyle behaviours. Our findings are supportive of a new conceptualisation of HL which argues that HL is not necessarily an inevitable accompaniment of ageing, but also a potential preventable lifestyle disease, paving the way for the term lifestyle-related HL, where lifestyle refers to social practices and ways of living adopted by individuals that reflect personal, group and socioeconomic identities, ${ }^{39}$ instead of the non-inclusive term 'age-related HL'. Future research in hearing health inequalities should investigate the role of the prolonged exposure to these modifiable lifestyle behaviours in the development of HL and the role of other comorbid chronic diseases in the elderly.

\section{Author affiliations}

${ }^{1}$ Centre for Primary Care and Health Services Research, Division of Population Health, School of Health Sciences, Faculty of Biology, Medicine and Health, University of Manchester, Manchester, UK

${ }^{2}$ Division of Informatics, Imaging \& Data Sciences, School of Health Sciences, Faculty of Biology, Medicine and Health, University of Manchester, Manchester, UK ${ }^{3} \mathrm{NIHR}$ Greater Manchester Patient Safety Translational Research Centre, Division of Pharmacy and Optometry, School of Health Sciences, Faculty of Biology, Medicine and Health, University of Manchester, Manchester, UK

${ }^{4}$ NIHR Greater Manchester Patient Safety Translational Research Centre, Division of Population Health, School of Health Sciences, Faculty of Biology, Medicine and Health, University of Manchester, Manchester, UK

Acknowledgements DT would like to acknowledge the contribution of Dr Piers Dawes and Prof Neil Pendleton, who had provided assistance in obtaining funding and were the former supervisors for her NIHR Manchester Biomedical Research Centre PhD Studentship, but did not fulfil the criteria set out in the Authorship Guidelines of The University of Manchester to be listed as authors.

Contributors DT, EK, DA and MP were responsible for developing the design of the study. DT was responsible for conducting the analyses, interpreting the results and drafting the manuscript. DT, EK, DA and MP critically revised the manuscript. All authors have read and approved the final manuscript.

Funding This research was funded by the NIHR Manchester Biomedical Research Centre (BRC).

Disclaimer The views expressed are those of the authors and not necessarily those of the BRC, the NIHR or the Department of Health. 
Competing interests No, there are no competing interests for any author.

Patient consent for publication Not required.

Provenance and peer review Not commissioned; externally peer reviewed.

Data availability statement The English Longitudinal Study of Ageing dataset is available via the UK Data Service (http://www.ukdataservice.ac.uk). Statistical code is available from the corresponding author at dialechti.tsimpida@manchester.ac.uk.

Open access This is an open access article distributed in accordance with the Creative Commons Attribution 4.0 Unported (CC BY 4.0) license, which permits others to copy, redistribute, remix, transform and build upon this work for any purpose, provided the original work is properly cited, a link to the licence is given, and indication of whether changes were made. See: https://creativecommons.org/ licenses/by/4.0/.

\section{REFERENCES}

1. WHO. Millions of people in the world have hearing loss that can be treated or prevented. 20. World Health Organization, 2013.

2. Wilson BS, Tucci DL, Merson MH, et al. Global hearing health care: new findings and perspectives. The Lancet 2017;390:2503-15.

3. Stevens G, Flaxman S, Brunskill E, et al. Global and regional hearing impairment prevalence: an analysis of 42 studies in 29 countries. Eur $J$ Public Health 2013;23:146-52.

4. Lutman ME, Spencer HS. Occupational noise and demographic factors in hearing. Acta Otolaryngol Suppl 1990;476:74-84.

5. Tsimpida D, Kaitelidou D, Galanis P. Determinants of health- related quality of life (HRQoL) among deaf and hard of hearing adults in Greece: a cross-sectional study. Arch Public Health 2018;76:55.

6. Scholes S, Biddulph J, Davis A, et al. Socioeconomic differences in hearing among middle-aged and older adults: cross-sectional analyses using the health survey for England. BMJ Open 2018;8:e019615.

7. Kawachi I, Subramanian SV, Almeida-Filho N. A glossary for health inequalities. J Epidemiol Community Health 2002;56:647-52.

8. Marmot MG, Allen J, Goldblatt P, et al. Fair Society, healthy lives: strategic review of health inequalities in England post-2010 2010.

9. Gopinath B, Flood VM, McMahon CM, et al. The effects of smoking and alcohol consumption on age-related hearing loss: the blue Mountains hearing study. Ear Hear 2010;31:277-82.

10. Zhan W, Cruickshanks KJ, Klein BEK, et al. Modifiable determinants of hearing impairment in adults. Prev Med 2011;53:338-42.

11. Curhan SG, Eavey R, Wang M, et al. Body mass index, waist circumference, physical activity, and risk of hearing loss in women. Am J Med 2013;126:1142.e1-1142.e8.

12. Galobardes B, Shaw M, Lawlor DA, et al. Indicators of socioeconomic position (Part 1). J Epidemiol Community Health 2006;60.

13. Health Profile for England, 2018Retrieved from. Available: https:// www.gov.uk/government/publications/health-profile-for-england2018

14. Poortinga $W$. The prevalence and clustering of four major lifestyle risk factors in an English adult population. Prev Med 2007:44:124-8.

15. Steptoe A, Breeze E, Banks J, et al. Cohort profile: the English longitudinal study of ageing. Int J Epidemiol 2013;42:1640-8.

16. Banks J, Blake M, Clemens S, et al. English Longitudinal Study of Ageing: Waves 0-8, 1998-2017. [data collection]. 29th Edition. SN: 5050: UK Data Service, 2018.

17. Siemens Audiologische Technik GmbH. Hear Check Screener User Guide. PUBLICIS; 2007 [on-line]. Available: http://www.connevans. info/image/connevans/38shearcheck.pdf

18. Fellizar-Lopez KR, Abes GT, Reyes-Quintos M, et al. Accuracy of Siemens HearCheck ${ }^{\mathrm{TM}}$ navigator as a screening tool for hearing loss. Philipp J Otolaryngol Head Neck Surg 2011;26:10-15.
19. Davis A, Smith P, Ferguson M, et al. Acceptability, benefit and costs of early screening for hearing disability: a study of potential screening tests and models. Health Technol Assess 2007;11.

20. Benova L, Grundy E, Ploubidis GB. Socioeconomic position and health-seeking behavior for hearing loss among older adults in England. GERONB 2015;70:443-52.

21. Bjorntorp P, Bray GA, Carroll KK, et al. Obesity : Preventing and Managing the Global Epidemic. WHO Technical Report Series 2000;92 https://doi.org/ISBN

22. Department of Health. UK Chief Medical Officers' Low Risk Drinking Guidelines, 2016Retrieved from. Available: https://assets.publishing. service.gov.uk/government/uploads/system/uploads/attachment data/file/545937/UK_CMOs_report.pdf

23. StataCorp. Stata statistical software: release 14. College Station, TX: StataCorp LP, 2015.

24. Andrade FCD, López-Ortega M. Educational differences in health among middle-aged and older adults in Brazil and Mexico. J Aging Health 2017;29:923-50.

25. Sung JH, Sim CS, Lee C-R, et al. Relationship of cigarette smoking and hearing loss in workers exposed to occupational noise. Ann Occup Environ Med 2013;25.

26. Martin LG, Schoeni RF, Andreski PM, et al. Trends and inequalities in late-life health and functioning in England. J Epidemiol Community Health 2012;66:874-80.

27. Pierre PV, Fridberger A, Wikman A, et al. Self-Reported hearing difficulties, main income sources, and socio-economic status; a cross-sectional population-based study in Sweden. BMC Public Health 2012;12:874.

28. Rosenhall U, Jönsson R, Söderlind O. Self-assessed hearing problems in Sweden: a demographic study. Int $\mathrm{J}$ Audiol 1999;38:328-34.

29. Davis AC. The prevalence of hearing impairment and reported hearing disability among adults in Great Britain. Int J Epidemiol 1989;18:911-7.

30. Cruickshanks KJ, Wiley TL, Tweed TS, et al. Prevalence of hearing loss in older adults in Beaver dam, Wisconsin. The epidemiology of hearing loss study. Am J Epidemiol 1998a;148:879-86.

31. Mamo SK, Nieman CL, Lin FR. Prevalence of untreated hearing loss by income among older adults in the United States. $J$ Health Care Poor Underserved 2016;27:1812-8.

32. Tsimpida D, Kaitelidou D, Galanis P. Barriers to the use of health services among deaf and hard of hearing adults in Greece: a crosssectional study. EJPCH 2018;6.

33. Üçler R, Turan M, Garça F, et al. The association of obesity with hearing thresholds in women aged 18-40 years. Endocrine 2016;52:46-53.

34. E Bishop C. The ear is a window to the heart: a modest argument for a closer integration of medical disciplines. Otolaryngology 2012;02:4172.

35. Hoffman HJ, Dobie RA, Losonczy KG, et al. Declining prevalence of hearing loss in US adults aged 20 to 69 years. JAMA Otolaryngol Head Neck Surg 2017;143:274-85.

36. Cruickshanks KJ, Dhar S, Dinces E, et al. Hearing impairment prevalence and associated risk factors in the Hispanic community health Study/Study of Latinos. JAMA Otolaryngol Head Neck Surg 2015:141:641-8.

37. Lin FR, Thorpe R, Gordon-Salant S, et al. Hearing loss prevalence and risk factors among older adults in the United States. $J$ Gerontol A Biol Sci Med Sci 2011;66A:582-90.

38. WHO. Fact sheets: non-communicable diseases, 2015Retrieved from. Available: https://www.who.int/topics/noncommunicable diseases/factsheets/en/

39. Gochman DS. Handbook of health behavior research II: provider determinants. Springer Science \& Business Media, 2013. 